\title{
Altered resting-state connectivity in subjects at ultra-high risk for psychosis: an fMRI study
}

\author{
Geumsook Shim¹, Jungsu S Oh², Wi Hoon Jung ${ }^{3}$, Joon Hwan Jang ${ }^{1}$, Chi-Hoon Choi ${ }^{4}$, Euitae Kim', Hye-Yoon Park', \\ Jung-Seok Choi ${ }^{1}$, Myung Hun Jung ${ }^{1}$, Jun Soo Kwon ${ }^{1,3,5^{*}}$
}

\begin{abstract}
Background: Individuals at ultra-high risk (UHR) for psychosis have self-disturbances and deficits in social cognition and functioning. Midline default network areas, including the medial prefrontal cortex and posterior cingulate cortex, are implicated in self-referential and social cognitive tasks. Thus, the neural substrates within the default mode network (DMN) have the potential to mediate self-referential and social cognitive information processing in UHR subjects.
\end{abstract}

Methods: This study utilized functional magnetic resonance imaging (fMRI) to investigate resting-state DMN and task-related network (TRN) functional connectivity in 19 UHR subjects and 20 matched healthy controls. The bilateral posterior cingulate cortex was selected as a seed region, and the intrinsic organization for all subjects was reconstructed on the basis of fMRI time series correlation.

Results: Default mode areas included the posterior/anterior cingulate cortices, the medial prefrontal cortex, the lateral parietal cortex, and the inferior temporal region. Task-related network areas included the dorsolateral prefrontal cortex, supplementary motor area, the inferior parietal lobule, and middle temporal cortex. Compared to healthy controls, UHR subjects exhibit hyperconnectivity within the default network regions and reduced anticorrelations (or negative correlations nearer to zero) between the posterior cingulate cortex and task-related areas.

Conclusions: These findings suggest that abnormal resting-state network activity may be related with the clinical features of UHR subjects. Neurodevelopmental and anatomical alterations of cortical midline structure might underlie altered intrinsic networks in UHR subjects.

\section{Background}

The 'default mode' is a term first coined by Raichle et al [1] to describe resting-state brain function and may be defined as a baseline condition of brain activity. The default mode network (DMN) refers to a set of functionally and anatomically organized neural regions that are active during a behavioral resting state and deactivated or suppressed during task performance $[1,2]$. The DMN most commonly includes the medial prefrontal cortex (mPFC) extending to ventral anterior cingulate cortex (ACC), the posterior cingulate cortex (PCC) extending to the precuneus (Pcu), and the lateral parietal cortex (LPC) [1]. Midline structures within the DMN have been implicated in self-referential cognitive and

\footnotetext{
* Correspondence: kwonjs@snu.ac.kr

'Department of Psychiatry, Seoul National University College of Medicine,

101 Daehak-no, Chongno-gu, Seoul, 110-744, Korea Full list of author information is available at the end of the article
}

emotional tasks $[3,4]$ as well as spontaneous thought processes known as mind wandering [5]. Self-referential processing mediated by the so-called cortical midline structures (CMS) is assumed to be the core of what is referred to as 'the self [6,7]. In contrast, lateral neocortical networks such as the dorsolateral prefrontal cortex (DLPFC) are active during tasks that demand attention and working memory $[8,9]$. Thus, these networks may be referred to, respectively, as 'task-negative' and 'taskpositive' networks, which are negatively correlated or anti-correlated [8].

The ability to understand another individual's mental state, called mentalizing or social cognition [10], is also an important aspect of resting-state brain function $[11,12]$. Human beings have a predisposition to engage in self-referential thought or social cognition, and the inclination to engage in such activity at rest (when not performing a task) may be mediated by the default
C Biomed Central 
system of the brain; the DMN [13]. Certain regions within the medial frontal lobe, including the ACC and the lateral parietal lobule, have been shown to be related to social cognition $[14,15]$. Functional imaging studies consistently identify increases in medial prefrontal cortical activity during social cognition tasks and have suggested that among such regions, the mPFC plays a predominant role in social cognition $[16,17]$.

The social brain hypothesis $[18,19]$ postulates that schizophrenia is a disorder of functional and structural connectivity within areas thought to regulate social cognition, such as the fronto-temporal and fronto-parietal cortical networks. Functional disintegration of these networks in patients with schizophrenia has been observed during performance of several types of cognitive tasks [20-22]. In addition, patients with schizophrenia consistently show evidence of abnormal resting-state functional connectivity [23-26], task-induced deactivation of CMS, and anti-correlation between DMN and taskrelated network (TRN) areas [25-27] when compared with healthy controls.

Over the last decade, the pre-onset, or prodromal, phase of schizophrenia has attracted considerable attention among researchers. Youths who are considered to be putatively prodromal have been identified using established criteria [28,29], and research on the characteristics of individuals at ultra-high risk (UHR) for psychosis has been conducted by several high-risk clinics. Neuroimaging studies have revealed that prior to the onset of psychosis, UHR youths already have brain abnormalities similar to those present in patients with schizophrenia [30-35]. These UHR youths also exhibit wide-ranging neuropsychological deficits comparable to those in patients with schizophrenia, although to a lesser degree $[36,37]$. These deficits include impaired social functioning and related problems with social skills [38-40], which are significant predictors of psychosis [41]. Recent studies from our group found that UHR individuals perform significantly worse during theory of mind (ToM) tasks, which measure the ability to conceptualize the mental state, beliefs, and intentions of other individuals [42]. Another fundamental feature of the prodromal phase of schizophrenia is self-disturbance $[43,44]$, which is considered to be a psychopathological marker of psychotic vulnerability [45].

Therefore, the functionality of the DMN in UHR subjects is of primary interest, as it holds the potential to reveal any abnormalities in the activity of neural substrates regulating self-referential and social cognitive processing. It is possible that alterations in DMN function contribute to social cognitive deficits, such as diminished ToM capabilities, and to social dysfunction, such as social withdrawal and impairment of life-role functioning. However, whether UHR subjects exhibit normal connectivity in the default network remains unknown. Thus, this study investigated DMN function in two carefully matched groups of UHR subjects and healthy controls. Because UHR subjects show impairments in social cognition and self-referential processing regulated by the DMN as well as in neurocognitive abilities moderated by the TRN, it is hypothesized that DMN and/or TRN functional connectivity is altered in UHR subjects compared with healthy controls.

\section{Methods \\ Participants}

A total of 23 subjects at UHR for psychosis and 39 healthy volunteers underwent a resting-state functional magnetic resonance imaging (fMRI) scan. Four UHR subjects were excluded after MRI scanning; one withdrew consent, another was assessed as having transitioned to psychosis prior to scanning, the third was scanned in an open-eye state, and the fourth showed excessive head motion. The remaining 19 UHR subjects fulfilled the following diagnostic criteria for at least one of three UHR groups according to the Comprehensive Assessment of At-Risk Mental States (CAARMS) instrument [29]: (1) attenuated psychosis group ( $\mathrm{n}=17),(2)$ brief limited intermittent psychotic symptoms $(\mathrm{n}=0)$, (3) vulnerability group $(n=5)$. Three subjects fulfilled the criteria for groups (1) and (3) concurrently. From among the 38 healthy volunteers (one was excluded as scanned in an open-eye state), 20 age-and gendermatched subjects were selected for between-group comparisons.

UHR subjects were recruited from the Seoul Youth Clinic (for detailed recruitment procedure and clinical assessments, see Chung et al [42] and Shin et al [35]). Seven subjects reported a family history of psychotic disorders; three had one first-degree relative with schizophrenia. Five UHR subjects were taking one or two psychotropic medications at the time of scanning, including anxiolytics $(\mathrm{n}=4)$ and atypical antipsychotics $(\mathrm{n}=3)$. The mean prodromal period for the 19 UHR subjects was 2.0 years $( \pm 1.9)$, and three subjects have since converted to psychosis during follow-up monitoring with a mean of 83.7 days $( \pm 53.9)$ after fMRI scanning. The healthy controls were recruited from an internet advertisement and screened using the Structured Clinical Interview for DSM-IV, non-patient edition [46]. All reported no personal or familial (i.e., first-to third-degree biological relatives) history of psychiatric disorders.

Participants were excluded if they had any lifetime diagnosis of substance abuse or dependence, neurological disease or brain injury, evidence of significant medical illness, or IQ less than 70. Several subjects had participated in previous studies from our group (one 
UHR subject and one control participated in Chung et al [42], two UHR subjects and five controls in Shin et al [35]). All participants provided written informed consent, including parental consent for those younger than 18 years of age. This study was approved by the Institutional Review Board at Seoul National University Hospital, and all procedures were performed in accordance with the current version of the Declaration of Helsinki.

\section{Image acquisition}

Functional images were acquired using a 1.5 T MAGNETOM Avanto scanner (Siemens, Erlangen, Germany). Whole brain functional scans during a behavioral resting state were acquired in 25 contiguous axial slices approximately parallel to the anterior-posterior commissure plane with interleaved multi-slice echo-planar imaging according to the following parameters: $\mathrm{TR}=2.34 \mathrm{~s}$, $\mathrm{TE}=52 \mathrm{~ms}$, field of view $=22 \mathrm{~cm}$, flip angle $=90^{\circ}$, voxel size $=3.44 \times 3.44 \times 5 \mathrm{~mm}$, slice thickness $=5$ $\mathrm{mm}$, no inter-slice gap. For each participant, a total of 120 volumes during $4.68 \mathrm{~min}$ were acquired. fMRI scanning was carried out in darkness, and the participants were explicitly instructed to keep their eyes closed, relax, and move as little as possible. T1-weighted highresolution structural images using a magnetization-prepared rapid acquisition gradient echo (MPRAGE) sequence were acquired in 176 contiguous axial slices for co-registration and normalization of the echo-planar images to the Montreal Neurologic Institute (MNI) template. Imaging parameters for the structural images were as follows: $\mathrm{TR}=1.16 \mathrm{~s}, \mathrm{TE}=4.76 \mathrm{~ms}$, field of view 23 $\mathrm{cm}$, flip angle $15^{\circ}$, voxel size $=0.45 \times 0.45 \times 0.90 \mathrm{~mm}$, slice thickness $=0.9 \mathrm{~mm}$, no inter-slice gap.

An average gap of 8.7 days $( \pm 10.0)$ occurred between clinical evaluation and fMRI scanning for all participants.

\section{fMRI preprocessing}

Functional imaging analysis was performed using SPM5 software (Wellcome Dept. of Imaging Neuroscience, London, UK: http://www.fil.ion.ucl.ac.uk/spm) and inhouse software running under the MATLAB environment (Mathworks, Inc.). For each subject, the first four images were discarded to eliminate the non-equilibrium effects of magnetization. The remaining functional images were corrected for differences in slice acquisition timing, which was followed by realignment to the middle image in the initial scan to correct for inter-scan movement and to remove signals correlated with head motion. Spatial normalization into the standard MNI template was performed and then smoothed using a Gaussian kernel of $6 \mathrm{~mm}$ full-width half-maximum to account for residual inter-subject differences.

\section{fMRI analysis}

\section{First-order analysis}

The intrinsic organization (i.e., functional connectivity map) was separately reconstructed in the UHR subjects and healthy controls using the PCC as a seed region [8] and then analyzing the functional connectivity pattern during rest. As a major research interest with regard to resting-state $\mathrm{fMRI}$ is in slow-changing temporal activation, the fMRI data were temporally band-pass filtered $(0.01-0.08 \mathrm{~Hz})[25,47]$ using finite impulse response filter to control for low-frequency drift and high-frequency noise. Generally, fMRI time series suffer from spurious correlations induced by partial volume effects of white matter, cerebrospinal fluid, and whole-brain functional activations. To account for this, multiple nuisance regressors [48] were generated from the segmentation results of T1 MPRAGE image using SPM5 software. A threshold value of 0.8 was applied for these segmentation maps, and "pure" white matter and cerebrospinal fluid masks that were less contaminated by other kinds of tissue were then extracted. For the generation of a whole-brain mask, a skull-stripping module called Brain Extraction tool in MRIcro software http://www.sph.sc.edu/comd/rorden/ mricro.html was used. Movement nuisance regressors were also estimated using the realignment parameters provided by SPM5 software. Subsequently, the nuisance regressors were fitted using the least squares method for the fMRI time series in each voxel and were then regressed out using equation 1 .

$$
\begin{aligned}
& y=H \mu+\varepsilon, \text { where } H=\left[\gamma_{-} c s f y \_w m \gamma_{-} w b\right. \text { tx ty tzrx ry rz] } \\
& \mu=\left(H^{T} H\right)^{-1} H^{T} t \\
& \hat{\varepsilon}=y-H \hat{\mu}
\end{aligned}
$$

Here, $y$ is the observed time series of fMRI, $H$ is the estimated nuisance regressors $\left(y_{-} c s f, y_{-} w m\right.$, and $y_{-} w b$ denote the average fMRI time series of CSF, skeletal white matter, and whole brain, respectively. $t x, t y, t z$ and $r x, r y, r z$ are translational and rotational movement regressors, respectively), $\mu$ is the mixture (coefficients) matrix of the nuisance regressors, and $\varepsilon$ is the residual time series that was extracted as the true fMRI activation free from nuisance confounds. Assuming normality of the residual signal, a least square estimator $\hat{\mu}$ of $\mu$ was used in order to estimate $\hat{\varepsilon}$, the estimator of true fMRI activation $\varepsilon$ that has no nuisance confounds.

The PCC, utilized as a seed region, was labeled using a Brodmann area (BA) atlas available in MRIcro software, which refers to the bilateral posterior cingulate as BA 23. The blood oxygen level-dependent (BOLD) time series of the voxels within this seed region were averaged to generate the reference time series. A correlation 
map was produced by computing the correlation coefficients between the reference time series and the time series from all other brain voxels. The resulting rho-maps were converted to $z$-values using a Fisher's rho-to- $z$ transform to improve normality. Statistical maps of the intrinsic networks for UHR subjects and healthy controls were created by entering the single-subject intrinsic network component into a voxel-wise onesample $t$-test using a criterion of $p<0.001$ (uncorrected for multiple comparisons) for each group. All results were depicted on the surface, which was extracted by FreeSurfer software using a canonical brain provided by MRIcro software. An image-processing technique termed maximum intensity projection was used to visualize the most significant voxel at each location between two brain surfaces (i.e., the white and pial surfaces, which are the boundaries between the white and gray matter and between the gray matter and cerebrospinal fluid, respectively).

\section{Second-order analysis}

The intrinsic networks for each subject from the firstlevel analysis were entered into a second-level random effects analysis using two-sample $t$-tests. Between-group comparisons of two intrinsic networks were restricted to the regions belonging to the intrinsic networks of control group with a threshold at $p<0.001$ (uncorrected) and a cluster size greater than 50 voxels.

\section{Results}

\section{Demographic and clinical characteristics}

Demographic and clinical characteristics for each group are provided in Table 1. All participants were right-handed, and the two groups were statistically similar in terms of parental socioeconomic status and IQ. However, compared to UHR subjects, healthy controls had a significantly higher number of educational years $(\mathrm{U}=84.00, p=0.002 * \%)$ and scored significantly higher in the Global Assessment of Functioning scale (GAF; $\mathrm{U}=12.50, p<0.001^{* * *}$ ) and the Social Functioning Scale (SFS; $t=-4.80, p<0.001^{* * *}$ ).

\section{Functional connectivity of the DMN and TRN}

Default mode activity was observed in brain regions previously defined as within the DMN (Figures 1 and 2) for both groups including the ACC, mPFC, Pcu, LPC, and the inferior temporal region. Although the default mode spatial maps look similar for UHR subjects and healthy controls, significant differences were observed in specific subregions of these areas (Figure 3). A two-sample $t$-test revealed that UHR subjects had significantly greater positive connectivity than did controls between the PCC seed region and other areas in the bilateral ACC, mPFC, $\mathrm{Pcu}$, and LPC (cluster-level $p<0.001$ ) (see Figure 4 for details). Healthy controls did not show greater positive connectivity than UHR subjects in any brain area.
Table 1 Demographic and clinical characteristics of subjects

\begin{tabular}{|c|c|c|c|c|c|c|}
\hline \multirow[t]{2}{*}{ Variables } & \multicolumn{2}{|c|}{$\begin{array}{l}\text { UHR subjects } \\
\quad(\mathrm{n}=19)\end{array}$} & \multicolumn{2}{|c|}{$\begin{array}{l}\text { Healthy } \\
\text { controls } \\
(n=20)\end{array}$} & \multicolumn{2}{|c|}{ Analysis } \\
\hline & Mean & SD & Mean & SD & $T / U / X^{2}$ & $p$ \\
\hline Male/Females & \multicolumn{2}{|c|}{$11 / 8$} & \multicolumn{2}{|c|}{$11 / 9$} & $0.03^{\mathrm{a}}$ & 0.86 \\
\hline Age (yrs) & 20.8 & 4.1 & 21.7 & 2.1 & $-0.77^{b}$ & 0.45 \\
\hline Handedness $(\mathrm{R} / \mathrm{L})^{\mathrm{e}}$ & \multicolumn{2}{|c|}{$19 / 0$} & \multicolumn{2}{|c|}{$20 / 0$} & & \\
\hline Parental SES & 3.0 & 1.2 & 3.2 & 1.2 & $165.00^{c}$ & 0.63 \\
\hline Educational years & 12.2 & 2.0 & 13.9 & 1.3 & $84.00^{c}$ & $0.002^{* *}$ \\
\hline $\mathrm{IQ}^{\mathrm{f}}$ & 109.2 & 17.7 & 106.4 & 12.7 & $176.50^{c}$ & 0.70 \\
\hline GAF & 52.3 & 11.6 & 89.8 & 2.0 & $12.50^{c}$ & $<0.001^{* *}$ \\
\hline $\mathrm{SFS}^{\mathrm{g}}$ & 100.39 & 10.21 & 115.09 & 6.76 & $-4.80^{d}$ & $<0.001^{* *}$ \\
\hline PANSS & 57.4 & 14.6 & & & & \\
\hline BPRS & 43.5 & 8.6 & & & & \\
\hline SAPS & 11.6 & 8.4 & & & & \\
\hline SANS & 28.4 & 16.5 & & & & \\
\hline CAARMS $^{h}$ & 46.5 & 18.8 & & & & \\
\hline
\end{tabular}

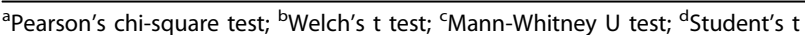
test.

${ }^{\text {e}}$ Assessed using Annett hand preference questionnaire [62].

${ }^{f}$ Estimated by Korean-Wechsler Adult Intelligence Scale-Revised (K-WAIS-R) [63].

${ }^{9}$ Average scores of the seven subscales, each of which was standardized and normalized with a mean of 100 and a SD of 15.

${ }^{\mathrm{h}} \mathrm{Scored}$ by adding the intensity rating scores.

Data were not available for some participants in parental SES (control $n=1$ ) and SFS (control $n=5$ ).

**p $<0.01$

UHR: ultra-high risk; SES: Hollingshead socioeconomic status (highest = 1, lowest = 5); IQ: intelligence quotient; GAF: Global Assessment of Functioning [64]; SFS: Social Functioning Scale [65]; PANSS: Positive and Negative Syndrome Scale [66]; BPRS: Brief Psychiatric Rating Scale (modified 24-item version, rating items 1-7) [67]; SAPS: Scale for the Assessment of Positive Symptoms [68]; SANS: Scale for the Assessment of Negative Symptoms [69]; CAARMS: Comprehensive Assessment of At-Risk Mental States.

Task-related or anti-correlated networks (Figures 1 and 2) and between-group differences (Figure 3) are also reported. The TRN areas are similar to previous reports $[23,25]$ and include the DLPFC, supplementary motor area, the inferior parietal lobule, and middle temporal cortex. For the between-group comparison, the bilateral DLPFC, the inferior parietal lobule, middle temporal cortex, and left supplementary motor area are significantly more (i.e., farther from zero) anti-correlated with the PCC in controls than in UHR subjects (cluster-level $p<0.001$ ) (see Figure 5 for details). Healthy controls did not exhibit a significantly reduced anti-correlation compared to UHR subjects.

\section{Discussion}

To our knowledge, this is the first study directly investigating resting-state functional connectivity of UHR subjects versus healthy controls. During a resting state, UHR subjects exhibited hyperconnectivity within DMN regions as well as reduced anti-correlations between the 


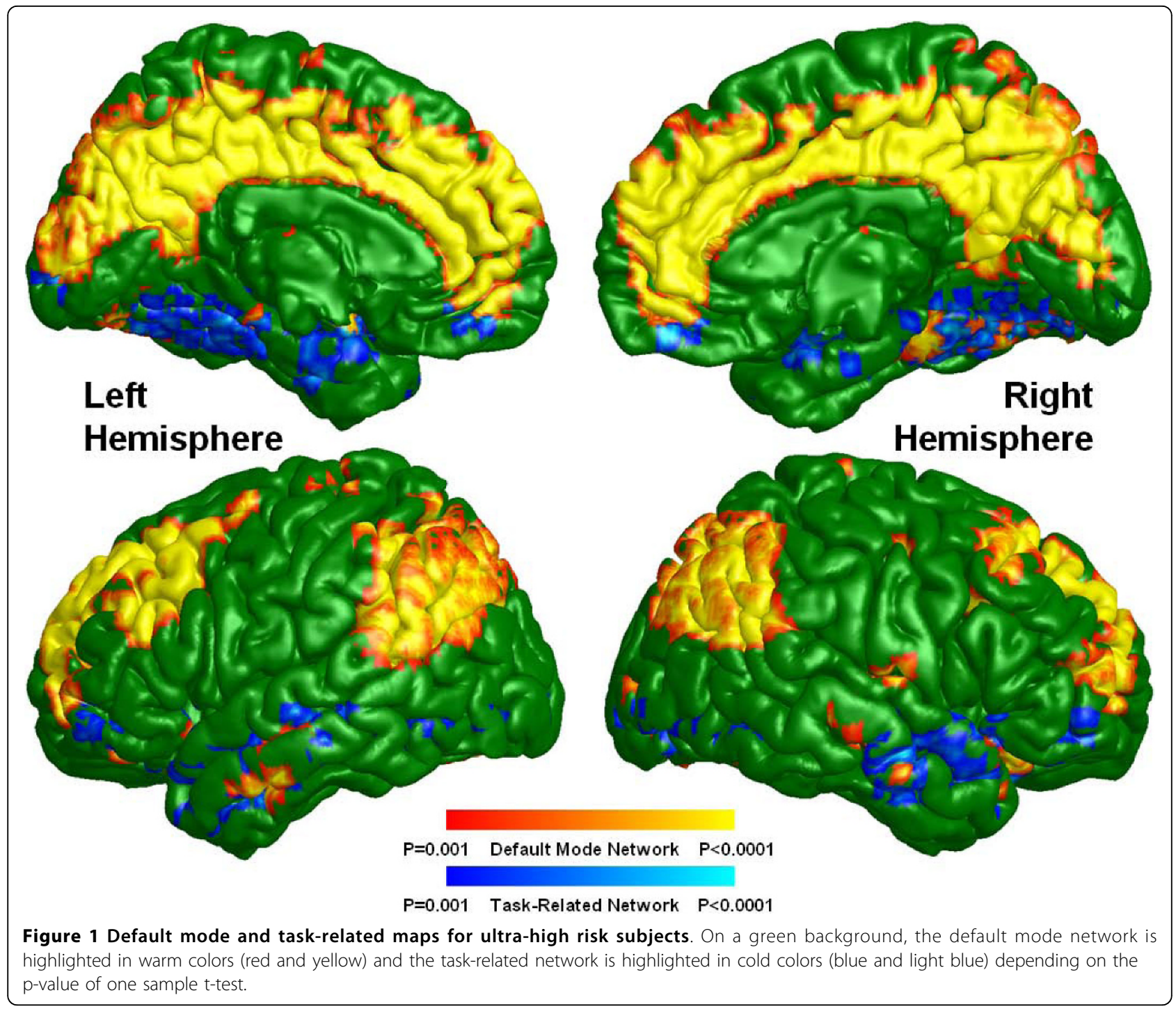

PCC and TRN regions compared with healthy volunteers.

Despite inconsistent findings with respect to functional connectivity in resting-state networks of patients with schizophrenia, the current results agree with those of Whitfield-Gabrieli et al [26] and Zhou et al [25]. In these studies, the majority of participants were also in their early twenties and in the early phase of schizophrenia with acute psychotic symptoms. Chronic schizophrenia subjects with mild psychotic symptoms (mean duration $\sim 10$ years) exhibited reduced connectivity between areas of the default network [23]. Together, these results demonstrate that the DMN is hyperconnective during the prodromal and early psychotic stages of the disease, in which subjective discomfort and psychotic symptoms manifest and prevail, and that the DMN areas become progressively less synchronized, as aging and illness is progressing. A recent fMRI study utilizing the n-back task found that patients with chronic schizophrenia show reduced activation in the right DLPFC and other frontal areas, but greater activation in the ACC and mPFC compared with controls [49]. This finding demonstrates a failure to effectively deactivate the ACC and MPFC, and implies that those with schizophrenia are inefficient in their resource allocation when moving away from internal mentation to perform difficult tasks in the external world $[49,50]$. However, greater task-induced deactivation in the mPFC in schizophrenia subjects was also reported, and the magnitude of this change was associated with task performance [24,27]. Thus, the hyperconnectivity of the DMN and the reduced anti-correlation between the DMN and TRN may be involved in the impaired neurocognitive function of UHR subjects [36,37]. An inability to 


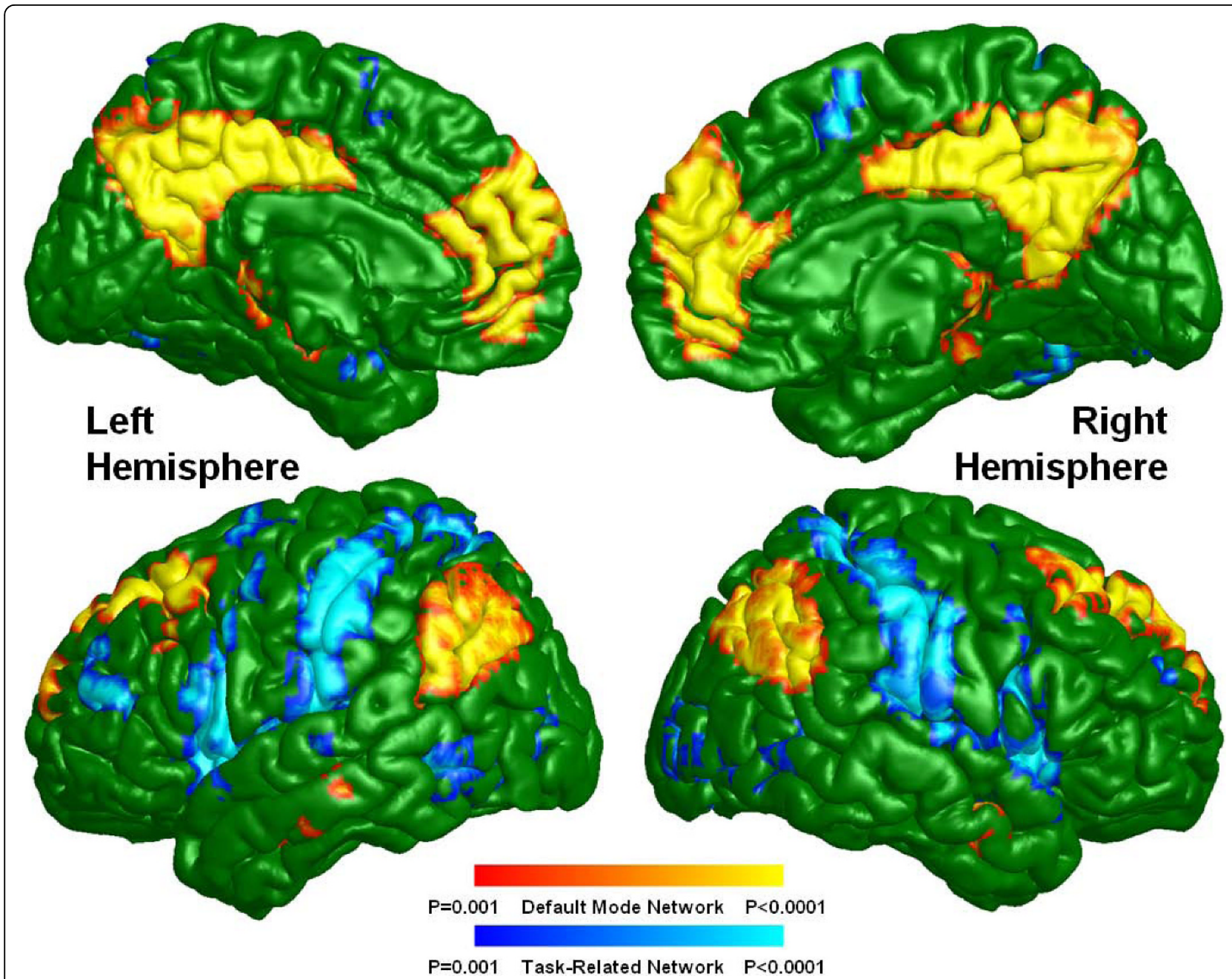

Figure 2 Default mode and task-related maps for healthy controls. The color codes for default mode and task-related networks are the same as for Figure 1.

synchronize the modulation between two anti-correlated areas may also mediate these impairments.

In social phobia patients, a significantly lower deactivation in the posterior cingulate regions and Pcu was found during a face perception task compared with the resting condition [51]. This suggests that the failure of social phobia patients to deactivate the DMN plays an important role in their persistent fear of social situations and their self-focused attention. Social cognitive deficits, social anxiety (heighted sensitivity to interpersonal cues), and other social impairments are also common in UHR individuals. However, the present study focused solely on functional connectivity in midline default areas, and functional activation during ToM tasks was not measured. Future fMRI studies may be considered combining the resting-state and ToM tasks to investigate the relationship between altered midline default mode connectivity and impaired social cognition in UHR subjects.

The presence of structural abnormalities in the MPFC and ACC are well established in schizophrenia [52]. Similarly, UHR individuals also exhibit neurodevelopmental anomalies in midline brain structures such as the ACC and cavum septi pellucid [30,31]. In addition, compared to healthy controls, these subjects exhibit significant cortical thinning in the prefrontal cortex, ACC, and LPC [53] as well as reduced gray-matter volume of the PCC and Pcu [32]. These structural and functional abnormalities of the default mode-related areas may be significant in the altered functional connectivity of the default mode in UHR subjects in the current study.

Basic self-disturbances, or anomalies of self-experience, are a prominent feature during the prodromal stage of psychosis, and it is suspected this is the core disturbance 


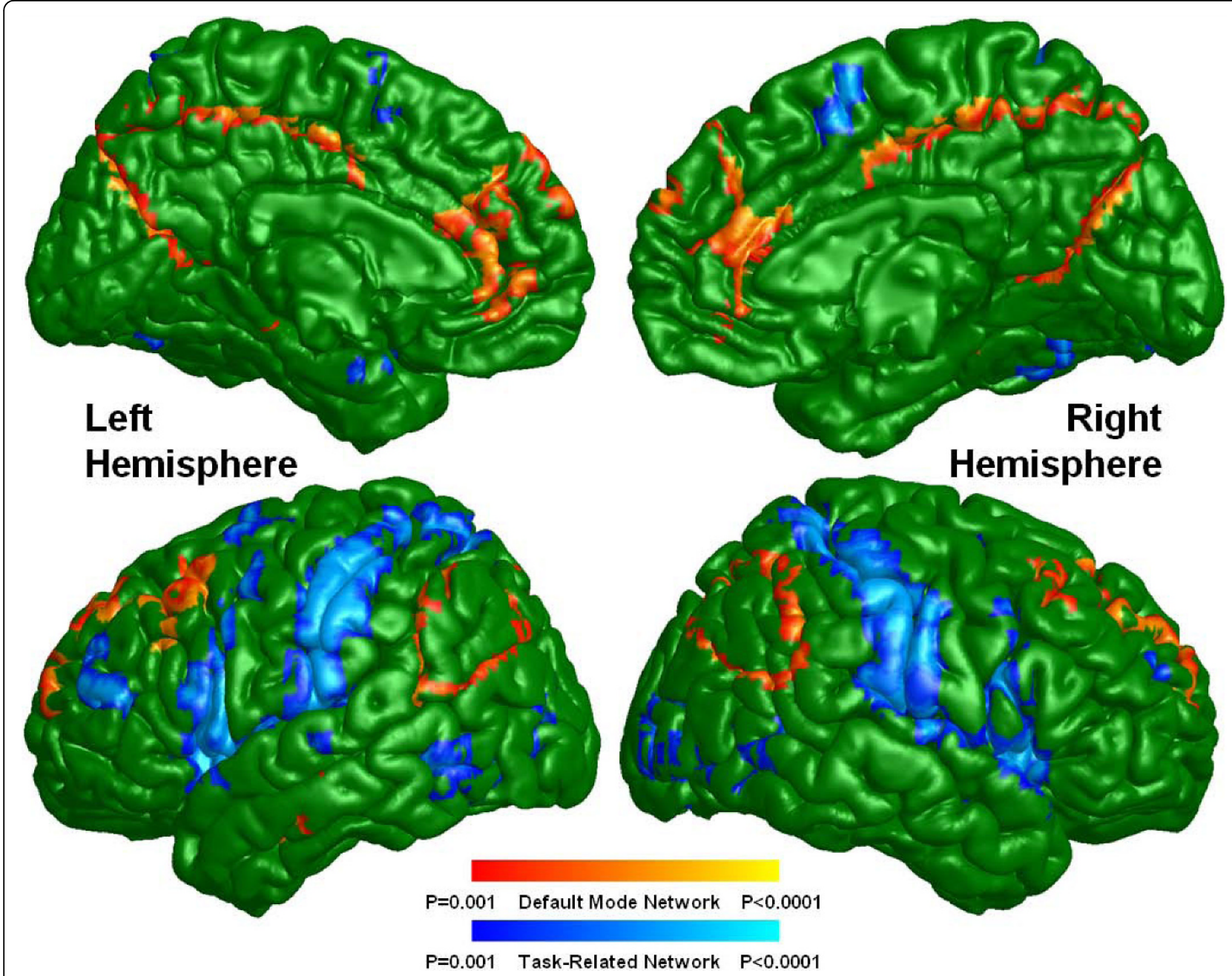

Figure 3 Differences between UHR subjects and healthy controls in the resting state functional networks. Default mode areas with increased connectivity in UHR subjects versus controls are shown in warm colors, and task-related areas with reduced anti-correlation in UHR subjects versus controls are shown in cold colors at the threshold of $p<0.001$ (uncorrected) and cluster size greater than 50 voxels. UHR: ultrahigh risk.

in the emergence of schizophrenia-spectrum disorders $[44,54,55]$. In addition, reality distortion, or the impairment of socioemotional information processing, was associated with medial prefrontal cortical hyperactivity during viewing of aversive pictures in schizophrenia or schizoaffective patients [56]. From this perspective, hyperconnectivity of midline default areas in UHR subjects seems to be related to the so-called prodromal selfdisturbance. However, further studies are necessary to apply a cognitive paradigm to subjective self-disturbance in UHR subjects to validate our assumption.

This study had several limitations. First, the interpretation of observed anti-correlations in resting state BOLD data is not straightforward [8]. Removal of spontaneous BOLD fluctuations common to the whole brain (the so-called global signal) mathematically mandates negative correlations, raising questions regarding the appropriateness of global signal regression and the interpretation of emerged anti-correlated networks [57]. However, anti-correlated networks were reported to be observed in the resting state without global regression [58], so cannot be fully explained as an artifact of global signal regression [57]. Although removal of the global signal facilitates the observation of true physiological relationships, great caution is required when comparing differences in anti-correlations between different clinical populations. Second, various conditions of internal mentation can influence resting-state brain activity, but the thoughts and feelings of subjects during the fMRI scanning period were not evaluated. Third, task paradigms including social cognition, self-reference, and subjective scales were not applied, limiting the analysis of the 


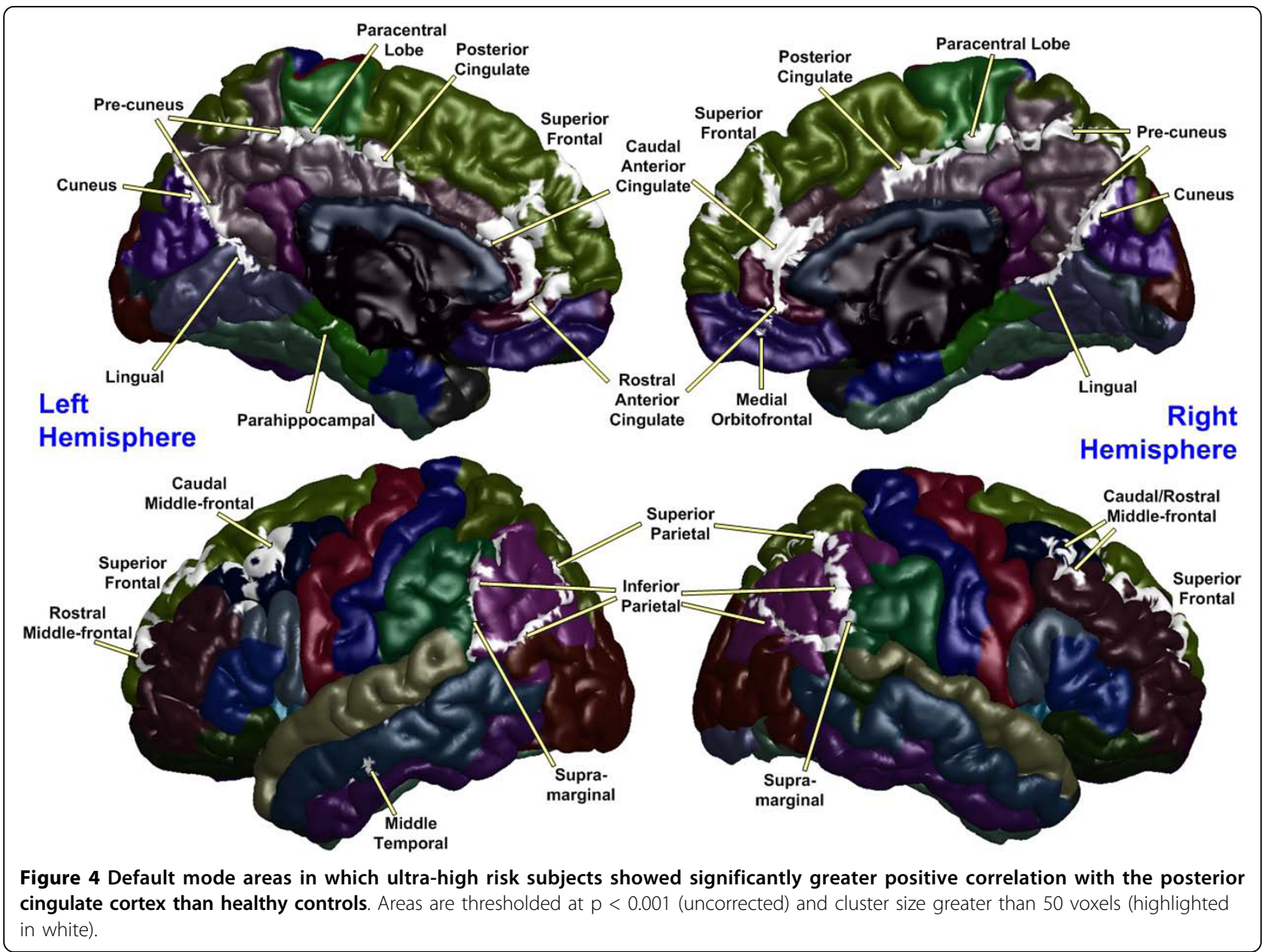

findings. Fourth, the reported conversion-to-psychosis rate $(16 \%)$ is much lower than that of UHR cohorts (over 40\%) tested in initial studies [59]. UHR status is not equivalent to being in the prodromal stage of schizophrenia or psychosis, so caution is needed in interpretation of these results. Finally, it is possible that medication could have influenced resting-state connectivity. However, 15 of 20 UHR subjects were drug-free, and the majority of previous studies investigating resting-state networks were conducted on medicated patients.

Several recent neuroimaging studies comparing UHR subjects who converted to psychosis (converters) with those who did not (non-converters) found that converters had less regional gray matter at baseline and greater gray matter reduction in longitudinal follow-ups than non-converters had $[32,60,61]$. Baseline ACC morphologic differences between converters and non-converters also predicted time-to-psychosis onset independent of symptomatology [33]. Similar to these comparison studies, longitudinal follow-up investigations of the current resting-state fMRI results may reveal differences within resting-state networks between converters and non-converters. This may provide valuable information about the properties of resting-state networks in terms of illness progression.

\section{Conclusions}

The current findings demonstrate significant alterations (i.e., functional pathology) of resting-state networks in UHR subjects and suggest that hyperconnectivity of the DMN and reduced anti-correlation between the DMN and TRN may play an important role in the clinical features of these subjects. Regions previously identified to be abnormal in UHR subjects also showed clear abnormalities in the DMN. Further resting-state fMRI studies that include social cognition tasks and subjective rating scales are necessary to further validate the interpretation of the present results.

\section{Acknowledgements}

This work was supported by World Class University program through the Korea Science and Engineering Foundation funded by the Ministry of Education, Science and Technology (R32-10142) and grant from the Seoul 


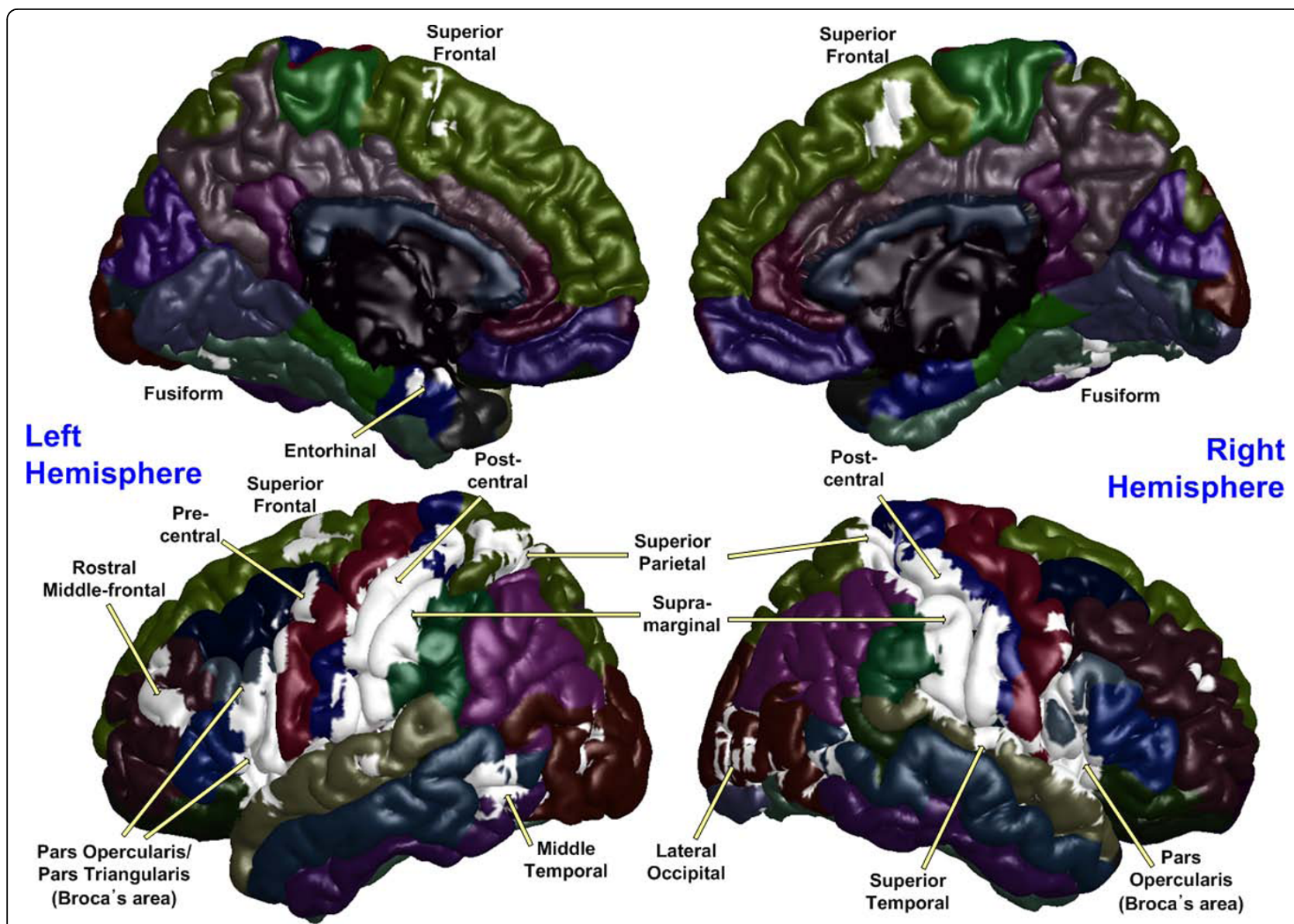

Figure 5 Task-related areas in which ultra-high risk subjects showed significantly reduced anti-correlations with the posterior cingulate cortex compared to healthy controls. Areas are thresholded at $p<0.001$ (uncorrected) and cluster size greater than 50 voxels (highlighted in white).

National University Hospital Research Fund (No: 03-2009-013). The authors would like to acknowledge all participants in the study.

\section{Author details}

'Department of Psychiatry, Seoul National University College of Medicine, 101 Daehak-no, Chongno-gu, Seoul, 110-744, Korea. ${ }^{2}$ BK21 Division of Human Life Science, Seoul National University, Seoul, Korea. ${ }^{3}$ Interdisciplinary Program in Brain Science, Seoul National University, Seoul, Korea. ${ }^{4}$ Department of Radiology, National Medical Center, Seoul, Korea. ${ }^{5}$ Department of Brain and Cognitive Sciences-World Class University Program, College of Natural Sciences, Seoul National University, Seoul, Korea.

\section{Authors' contributions}

GS was involved in conceiving the study, analyzing the data as well as writing the manuscript. JSO processed and analyzed the data, and helped to draft the manuscript. GS and JSO contributed equally to this work. WHJ participated in MRI acquisition, pre-processing and analysis, and assisted with interpretation of study findings. CHC aided in initial MRI data collection, supervised the MR scanning, and participated in the data analysis. JHJ, EK, HYP, JSC and MHJ recruited subjects, undertook clinical assessments of the participants and substantially contributed in writing the manuscript. JSK developed the Seoul Youth Clinic, designed and supervised the overall study, and reviewed the manuscript. All authors have read and approved the final manuscript.

\section{Competing interests}

The authors declare that they have no competing interests.
Received: 8 July 2010 Accepted: 11 October 2010 Published: 11 October 2010

\section{References}

1. Raichle ME, MacLeod AM, Snyder AZ, Powers WJ, Gusnard DA, Shulman GL: A default mode of brain function. Proc Natl Acad Sci USA 2001, 98:676-682.

2. Gusnard DA, Raichle ME: Searching for a baseline: functional imaging and the resting human brain. Nat Rev Neurosci 2001, 2:685-694.

3. Gusnard DA, Akbudak E, Shulman GL, Raichle ME: Medial prefrontal cortex and self-referential mental activity: relation to a default mode of brain function. Proc Natl Acad Sci USA 2001, 98:4259-4264.

4. Kelley WM, Macrae CN, Wyland CL, Caglar S, Inati S, Heatherton TF: Finding the self? An event-related fMRI study. J Cogn Neurosci 2002, 14:785-794.

5. Mason MF, Norton MI, Van Horn JD, Wegner DM, Grafton ST, Macrae CN: Wandering minds: the default network and stimulus-independent thought. Science 2007, 315:393-395.

6. Northoff G, Heinzel A, de Greck M, Bermpohl F, Dobrowolny H, Panksepp J: Self-referential processing in our brain-a meta-analysis of imaging studies on the self. Neuroimage 2006, 31:440-457.

7. D'Argembeau A, Collette F, Van der Linden M, Laureys S, Del Fiore G, Degueldre C, Luxen A, Salmon E: Self-referential reflective activity and its relationship with rest: a PET study. Neuroimage 2005, 25 : 616-624.

8. Fox MD, Snyder AZ, Vincent JL, Corbetta M, Van Essen DC, Raichle ME: The human brain is intrinsically organized into dynamic, anticorrelated functional networks. Proc Natl Acad Sci USA 2005, 102:9673-9678. 
9. Fransson P: Spontaneous low-frequency BOLD signal fluctuations: an fMRI investigation of the resting-state default mode of brain function hypothesis. Hum Brain Mapp 2005, 26:15-29.

10. Frith $U$, Frith $C D$ : Development and neurophysiology of mentalizing. Philos Trans R Soc Lond B Biol Sci 2003, 358:459-473.

11. Broyd SJ, Demanuele C, Debener S, Helps SK, James CJ, Sonuga-Barke EJ: Default-mode brain dysfunction in mental disorders: a systematic review. Neurosci Biobehav Rev 2009, 33:279-296.

12. Buckner RL, Andrews-Hanna JR, Schacter DL: The brain's default network: anatomy, function, and relevance to disease. Ann N Y Acad Sci 2008, 1124:1-38.

13. Schilbach L, Eickhoff SB, Rotarska-Jagiela A, Fink GR, Vogeley K: Minds at rest? Social cognition as the default mode of cognizing and its putative relationship to the "default system" of the brain. Conscious Cogn 2008, 17:457-467.

14. Adolphs R: Cognitive neuroscience of human social behaviour. Nat Rev Neurosci 2003, 4:165-178.

15. Amodio DM, Frith CD: Meeting of minds: the medial frontal cortex and social cognition. Nat Rev Neurosci 2006, 7:268-277.

16. Lee $\mathrm{KH}$, Brown $\mathrm{WH}$, Egleston $\mathrm{PN}$, Green RD, Farrow TF, Hunter MD, Parks RW, Wilkinson ID, Spence SA, Woodruff PW: A functional magnetic resonance imaging study of social cognition in schizophrenia during an acute episode and after recovery. Am J Psychiatry 2006, 163:1926-1933.

17. Frith CD, Frith U: Interacting minds-a biological basis. Science 1999, 286:1692-1695.

18. Burns J: The social brain hypothesis of schizophrenia. World Psychiatry 2006, 5:77-81.

19. Brothers $L$ : The social brain: A project for integrating primate behavior and neurophysiology in a new domain. Concepts in Neuroscience 1990, 1:27-51.

20. Lawrie SM, Buechel C, Whalley HC, Frith CD, Friston KJ, Johnstone EC: Reduced frontotemporal functional connectivity in schizophrenia associated with auditory hallucinations. Biol Psychiatry 2002, 51: 1008-1011.

21. Stephan KE, Baldeweg T, Friston KJ: Synaptic plasticity and dysconnection in schizophrenia. Biol Psychiatry 2006, 59:929-939.

22. Kim JJ, Kwon JS, Park HJ, Youn T, Kang DH, Kim MS, Lee DS, Lee MC: Functional disconnection between the prefrontal and parietal cortices during working memory processing in schizophrenia: $\mathrm{a}[15(\mathrm{O})] \mathrm{H} 2 \mathrm{O}$ PET study. Am J Psychiatry 2003, 160:919-923.

23. Bluhm RL, Miller J, Lanius RA, Osuch EA, Boksman K, Neufeld RW, Theberge J, Schaefer B, Williamson P: Spontaneous low-frequency fluctuations in the BOLD signal in schizophrenic patients: anomalies in the default network. Schizophr Bull 2007, 33:1004-1012.

24. Garrity AG, Pearlson GD, McKiernan K, Lloyd D, Kiehl KA, Calhoun VD: Aberrant "default mode" functional connectivity in schizophrenia. Am J Psychiatry 2007, 164:450-457.

25. Zhou Y, Liang M, Tian L, Wang K, Hao Y, Liu H, Liu Z, Jiang T: Functional disintegration in paranoid schizophrenia using resting-state fMRI. Schizophr Res 2007, 97:194-205.

26. Whitfield-Gabrieli S, Thermenos HW, Milanovic S, Tsuang MT, Faraone SV, McCarley RW, Shenton ME, Green Al, Nieto-Castanon A, LaViolette P, et al: Hyperactivity and hyperconnectivity of the default network in schizophrenia and in first-degree relatives of persons with schizophrenia. Proc Natl Acad Sci USA 2009, 106:1279-1284.

27. Harrison BJ, Yucel M, Pujol J, Pantelis C: Task-induced deactivation of midline cortical regions in schizophrenia assessed with fMRI. Schizophr Res 2007, 91:82-86

28. Miller TJ, McGlashan TH, Rosen JL, Somjee L, Markovich PJ, Stein K, Woods SW: Prospective diagnosis of the initial prodrome for schizophrenia based on the Structured Interview for Prodromal Syndromes: preliminary evidence of interrater reliability and predictive validity. Am J Psychiatry 2002, 159:863-865.

29. Yung AR, Yuen HP, McGorry PD, Phillips LJ, Kelly D, Dell'Olio M, Francey SM, Cosgrave EM, Killackey E, Stanford C, et al: Mapping the onset of psychosis: the comprehensive assessment of at-risk mental states. Aust $N$ Z J Psychiatry 2005, 39:964-971.

30. Yucel M, Wood SJ, Phillips LJ, Stuart GW, Smith DJ, Yung A, Velakoulis D, McGorry PD, Pantelis C: Morphology of the anterior cingulate cortex in young men at ultra-high risk of developing a psychotic illness. $\mathrm{Br} J$ Psychiatry 2003, 182:518-524.
31. Choi JS, Kang DH, Park JY, Jung WH, Choi CH, Chon MW, Jung MH, Lee JM, Kwon JS: Cavum septum pellucidum in subjects at ultra-high risk for psychosis: compared with first-degree relatives of patients with schizophrenia and healthy volunteers. Prog Neuropsychopharmacol Biol Psychiatry 2008, 32:1326-1330.

32. Borgwardt SJ, Riecher-Rossler A, Dazzan P, Chitnis X, Aston J, Drewe M, Gschwandtner U, Haller S, Pfluger M, Rechsteiner E, et al: Regional gray matter volume abnormalities in the at risk mental state. Biol Psychiatry 2007, 61:1148-1156.

33. Fornito A, Yung AR, Wood SJ, Phillips LJ, Nelson B, Cotton S, Velakoulis D, McGorry PD, Pantelis C, Yucel M: Anatomic abnormalities of the anterior cingulate cortex before psychosis onset: an MRI study of ultra-high-risk individuals. Biol Psychiatry 2008, 64:758-765.

34. Morey RA, Inan S, Mitchell TV, Perkins DO, Lieberman JA, Belger A: Imaging frontostriatal function in ultra-high-risk, early, and chronic schizophrenia during executive processing. Arch Gen Psychiatry 2005, 62:254-262.

35. Shin KS, Kim JS, Kang DH, Koh Y, Choi JS, O'Donnell BF, Chung CK, Kwon JS: Pre-attentive auditory processing in ultra-high-risk for schizophrenia with magnetoencephalography. Biol Psychiatry 2009, 65:1071-1078.

36. Niendam TA, Bearden CE, Zinberg J, Johnson JK, O'Brien M, Cannon TD: The course of neurocognition and social functioning in individuals at ultra high risk for psychosis. Schizophr Bull 2007, 33:772-781.

37. Hawkins KA, Addington J, Keefe RS, Christensen B, Perkins DO, Zipurksy R, Woods SW, Miller TJ, Marquez E, Breier A, McGlashan TH:

Neuropsychological status of subjects at high risk for a first episode of psychosis. Schizophr Res 2004, 67:115-122.

38. Pinkham AE, Penn DL, Perkins DO, Graham KA, Siegel M: Emotion perception and social skill over the course of psychosis: a comparison of individuals "at-risk" for psychosis and individuals with early and chronic schizophrenia spectrum illness. Cogn Neuropsychiatry 2007, 12:198-212.

39. Addington J, Penn D, Woods SW, Addington D, Perkins DO: Social functioning in individuals at clinical high risk for psychosis. Schizophr Res 2008, 99:119-124.

40. Shim G, Kang DH, Chung YS, Yoo SY, Shin NY, Kwon JS: Social functioning deficits in young people at risk for schizophrenia. Aust N Z J Psychiatry 2008, 42:678-685.

41. Yung AR, Phillips LJ, Yuen HP, Francey SM, McFarlane CA, Hallgren M, McGorry PD: Psychosis prediction: 12-month follow up of a high-risk ("prodromal") group. Schizophr Res 2003, 60:21-32

42. Chung YS, Kang DH, Shin NY, Yoo SY, Kwon JS: Deficit of theory of mind in individuals at ultra-high-risk for schizophrenia. Schizophr Res 2008, 99:111-118.

43. Parnas J, Jansson L, Sass LA, Handest P: Self-experience in the prodromal phases of schizophrenia: A pilot study of first-admissions. Neurology, Psychiatry and Brain Research 1998, 6:97-106.

44. Moller $P$, Husby $R$ : The initial prodrome in schizophrenia: searching for naturalistic core dimensions of experience and behavior. Schizophr Bull 2000, 26:217-232.

45. Nelson B, Yung AR, Bechdolf A, McGorry PD: The phenomenological critique and self-disturbance: implications for ultra-high risk ("prodrome") research. Schizophr Bull 2008, 34:381-392.

46. First MB, Spitzer RL, Gibbon M, Williams JBW: Structured Clinical Interview for DSM-IV Axis I Disorders, Non-Patient Edition (SCID-I/NP version 2.0-8/ 98 revision). New York: Biometrics Research, New York State Psychiatric Institute 1998.

47. Auer DP: Spontaneous low-frequency blood oxygenation leveldependent fluctuations and functional connectivity analysis of the 'resting' brain. Magn Reson Imaging 2008, 26:1055-1064.

48. Lund TE, Madsen KH, Sidaros K, Luo WL, Nichols TE: Non-white noise in fMRI: does modelling have an impact? Neuroimage 2006, 29:54-66.

49. Pomarol-Clotet E, Salvador R, Sarro S, Gomar J, Vila F, Martinez A, Guerrero A, Ortiz-Gil J, Sans-Sansa B, Capdevila A, et al: Failure to deactivate in the prefrontal cortex in schizophrenia: dysfunction of the default mode network? Psychol Med 2008, 38:1185-1193.

50. Menzies L, Ooi C, Kamath S, Suckling J, McKenna P, Fletcher P, Bullmore E, Stephenson C: Effects of gamma-aminobutyric acid-modulating drugs on working memory and brain function in patients with schizophrenia. Arch Gen Psychiatry 2007, 64:156-167

51. Gentili C, Ricciardi E, Gobbini Ml, Santarelli MF, Haxby JV, Pietrini $P$, Guazzelli M: Beyond amygdala: default mode network activity differs 
between patients with social phobia and healthy controls. Brain Res Bull 2009, 79:409-413.

52. Shenton ME, Dickey CC, Frumin M, McCarley RW: A review of MRI findings in schizophrenia. Schizophr Res 2001, 49:1-52.

53. Jung WH, Kim JS, Jang JH, Choi JS, Jung MH, Park JY, Han JY, Choi CH, Kang DH, Chung CK, Kwon JS: Cortical thickness reduction in individuals at ultra-high-risk for psychosis. Schizophr Bull .

54. Nelson B, Fornito A, Harrison BJ, Yucel M, Sass LA, Yung AR, Thompson A, Wood SJ, Pantelis C, McGorry PD: A disturbed sense of self in the psychosis prodrome: linking phenomenology and neurobiology. Neurosci Biobehav Rev 2009, 33:807-817.

55. Parnas J, Handest P: Phenomenology of anomalous self-experience in early schizophrenia. Compr Psychiatry 2003, 44:121-134.

56. Taylor SF, Welsh RC, Chen AC, Velander AJ, Liberzon I: Medial frontal hyperactivity in reality distortion. Biol Psychiatry 2007, 61:1171-1178.

57. Fox MD, Zhang D, Snyder AZ, Raichle ME: The global signal and observed anticorrelated resting state brain networks. J Neurophysiol 2009, 101:3270-3283

58. Chang C, Glover GH: Relationship between respiration, end-tidal $\mathrm{CO} 2$, and BOLD signals in resting-state fMRI. Neuroimage 2009, 47:1381-1393.

59. Yung AR, Nelson B, Stanford C, Simmons MB, Cosgrave EM, Killackey E, Phillips L, Bechdolf A, Buckby J, McGorry PD: Validation of "prodromal" criteria to detect individuals at ultra high risk of psychosis: 2 year follow-up. Schizophr Res 2008, 105:10-17.

60. Pantelis C, Velakoulis D, McGorry PD, Wood SJ, Suckling J, Phillips $\amalg$, Yung AR, Bullmore ET, Brewer W, Soulsby B, et al: Neuroanatomical abnormalities before and after onset of psychosis: a cross-sectional and longitudinal MRI comparison. Lancet 2003, 361:281-288,

61. Takahashi T, Wood SJ, Yung AR, Soulsby B, McGorry PD, Suzuki M Kawasaki Y, Phillips $L$, Velakoulis D, Pantelis C: Progressive gray matter reduction of the superior temporal gyrus during transition to psychosis. Arch Gen Psychiatry 2009, 66:366-376.

62. Annett M: A classification of hand preference by association analysis. $\mathrm{Br} J$ Psychol 1970, 61:303-321.

63. Kim JS, Lee YS: Validity of short forms of the Korean-Wechsler Adult Intelligence Scale. Korean J Clin Psychol 1995, 14:111-116.

64. American Psychiatric Association: Diagnostic and Statistical Manual of Mental Disorders, 4th ed (DSM-IV). Washington, DC: American Psychiatric Press 1994.

65. Birchwood M, Smith J, Cochrane R, Wetton S, Copestake S: The Social Functioning Scale. The development and validation of a new scale of social adjustment for use in family intervention programmes with schizophrenic patients. Br J Psychiatry 1990, 157:853-859.

66. Kay SR, Fiszbein A, Opler LA: The positive and negative syndrome scale (PANSS) for schizophrenia. Schizophr Bull 1987, 13:261-276.

67. McGorry PD, Goodwin RJ, Stuart GW: The development, use, and reliability of the brief psychiatric rating scale (nursing modification)-an assessment procedure for the nursing team in clinical and research settings. Compr Psychiatry 1988, 29:575-587.

68. Andreasen NC: The Scale of the Assessment of Positive Symptoms. lowa City: University of lowa 1984

69. Andreasen NC: The Scale of the Assessment of Negative Symptoms. lowa City: University of lowa 1983

doi:10.1186/1744-9081-6-58

Cite this article as: Shim et al:: Altered resting-state connectivity in subjects at ultra-high risk for psychosis: an fMRI study. Behavioral and Brain Functions 2010 6:58

\section{Submit your next manuscript to BioMed Central and take full advantage of:}

- Convenient online submission

- Thorough peer review

- No space constraints or color figure charges

- Immediate publication on acceptance

- Inclusion in PubMed, CAS, Scopus and Google Scholar

- Research which is freely available for redistribution

Submit your manuscript at www.biomedcentral.com/submit 